\title{
LncRNA MAGI2-AS3 is downregulated in non-small cell lung cancer and may be a sponge of miR-25
}

\author{
Yutong Sui ${ }^{1}$, Wencheng $\mathrm{Chi}^{2,3}$, Li Feng ${ }^{1}$ and Jiakang Jiang ${ }^{2,3^{*}}$ (D)
}

\begin{abstract}
Background: This study aimed to investigate the role of InCRNA MAGI2-AS3 in non-small cell lung cancer (NSCLC).

Methods: Expression levels of MAGI2-AS3 and RECK mRNA in two types of tissues (non-tumor and NCSLC) were measured by qPCR. To further investigate the interaction between MAGI2-AS3 and RECK, MAGI2-AS3 and RECK expression vectors were transfected into H1993 cells.

Results: We found that MAGI2-AS3 and RECK were upregulated and positively correlated in NSCLC. In NSCLC cells, MAGI2-AS3 overexpression led to upregulated RECK. Bioinformatics analysis showed that MAGI2-AS3 may bind miR25, which can directly target RECK. In NSCLC cells, miR-25 overexpression led to downregulated RECK and attenuated the effects of MAGI2-AS3 overexpression, while MAGI2-AS3 and miR-25 failed to affect each other. Cell invasion and migration analysis showed decreased NSCLC cell invasion and migration rates after MAGI2-AS3 and RECK overexpression. MiR-25 showed opposite role and reduced the effects of MAGI2-AS3 overexpression.

Conclusion: Therefore, MAGI2-AS3 may sponge miR-25 to upregulate RECK, thereby inhibiting NSCLC cell invasion and migration.

Trial registration: HLJCM20163358592, registered by First Affiliated Hospital, Heilongjiang University of Chinese Medicine at March 3, 2016, prospectively.
\end{abstract}

Keywords: Non-small cell lung cancer, MAGI2-AS3, miR-25, RECK, Sponge

\section{Background}

Lung cancer is the most common cause of deaths in cancer patients [1]. Every year, lung cancer causes more than 1.6 million deaths, which accounts for about $20 \%$ of all deaths causes by all cancers [2]. Due to the fact that most lung cancer patients are diagnosed when tumor metastasis already exist, it is estimated that only less than $5 \%$ of lung cancer patients can live longer than 5 years after the initial diagnosis [3]. Non-small-cell lung cancers (NSCLCs) are the major subgroup of lung cancer [3]. Although smoking is the major risk factor for NSCLC [4], NSCLC also

\footnotetext{
* Correspondence: khnrmrgw090120@126.com

${ }^{2}$ Heilongjiang University of Chinese Medicine, Harbin 150040, Heilongjiang province, China

${ }^{3}$ First Affiliated Hospital, Heilongjiang University of Chinese Medicine, Heping Road 26, Harbin 150040, Heilongjiang province, China

Full list of author information is available at the end of the article
}

affects never-smokers [5], indicating the involvement of genetic factors in this disease [6].

RECK, also known as reversion-inducing-cysteine-rich protein with kazal motifs, has been characterized as a metastasis suppressor [7]. RECK interacts matrix metalloproteinase to facilitate cell invasion $[8,9]$. RECK in cancer can be targeted by certain oncogenic miRNAs, such as miRNA-182-5p and miR-25 [10, 11]. In gastric cancer, miR-25 targets to RECK to promote cancer cell motility and growth [11]. It is known that the functions of miRNAs can be attenuated by their sponges, such as long (> $200 \mathrm{nt}$ ) non-coding RNAs [12]. LncRNA MAGI2-AS3 has been characterized as a oncogenic lncRNA in breast cancer, bladder cancer and liver cancer [13-15]. Our bioinformatics analysis showed that MAGI2-AS3 may interact with miR-25. This study aimed to investigate the interaction between miR-25 and MAGI2-AS3 in NSCLC.

(c) The Author(s). 2020 Open Access This article is distributed under the terms of the Creative Commons Attribution 4.0 International License (http://creativecommons.org/licenses/by/4.0/), which permits unrestricted use, distribution, and 


\section{Methods}

\section{Study subjects}

The subjects of the present study were 78 NSCLC patients (gender: 48 males and 30 females; age: 34 to 66 years; mean: $50.2 \pm 5.6$ year) who were admitted to Heilongjiang University of Chinese Medicine between May 2016 and January 2019. Those 78 patients were selected according to: inclusion criteria: 1) newly diagnosed NSCLC; 2) no therapies received before admission, and exclusion criteria: 1) complicated with other diseases; 2) recurrent NSCLC; 3) therapies were initiated; 4) transferred from other hospitals. Those 78 NSCLC included $14,15,23$ and 26 cases at stage (AJCC) I-IV, respectively. All the 78 patients were informed with experimental principle. Before the admission of patients, Ethics Committee of Heilongjiang University of Chinese Medicine approved this study.

\section{NSCLC tissues and cells}

All in vitro studies were performed using H1993 human NSCLC (ATCC, USA) cell lines. Cells were cultivated in the mixture of $90 \%$ RPMI-1640 medium and 10\% (W/V) FBS. Cells were cultivated at $37{ }^{\circ} \mathrm{C}$ in an incubator $(95 \%$ humidity and $5 \% \mathrm{CO}_{2}$ ).

To perform in vivo gene expression analysis, biopsy was performed on all patients to obtain both non-tumor and NSCLC tissues. Weight of tissues ranged from 16 $\mathrm{mg}$ to $21 \mathrm{mg}$. Tissues were tested by pathologists. Before used, all tissues were kept in liquid nitrogen.

\section{Prediction of the interaction between MAGI2-AS3 and miR-25}

To predict the possible interaction between MAGI2-AS3 (NCBI Accession: NR_038343.2) and miR-25 (miRbase Accession: MI0000082), MAGI2-AS3 (long sequence) and miR-25 (short sequence) were inputted into IntaRNA (http://rna.informatik.uni-freiburg.de/IntaRNA/Input.jsp) RNA-RNA interaction online prediction program. All the parameters were default.

\section{Vectors and miRNA mimic}

Negative control miRNA and miR-25 mimic (miRbase Accession: MI0000082) were from Sigma-Aldrich (USA). MAGI2-AS3 (NCBI Accession: NR_038343.2) and RECK (NCBI Accession: NM_021111.3) expression pcDNA3 vectors were constructed by GenePharma (Shanghai, China).

\section{Transient transfections}

H1993 cells were harvested at confluence of $70-80 \%$. Cells were counted and $5 \times 10^{5}$ cells were transfected with $40 \mathrm{nM}$ negative control miRNA (negative control, $\mathrm{NC}$ ), or miR-25 mimic (miR-25 group), or $10 \mathrm{nM}$ empty pcDNA3 vector (NC), or $10 \mathrm{nM}$ MAGI2-AS3 (MAGI2-
AS3 group) or RECK expression (RECK group) pcDNA3 vectors through lipofectamine 2000 (Sangon) mediated transient transfections. Cells without transfections were control (C) group cells. The interval between transfections and following experiments was $24 \mathrm{~h}$.

\section{RNA extractions}

RNAs in H1993 cells as well as non-tumor and NSCLC tissues were extracted using Trizol (Invitrogen, USA). All RNA samples were precipitated using 85\% ethanol. $85 \%$ ethanol was also used in the washing step. With the use of $85 \%$ ethanol, all types of RNAs including miRNAs were harvested.

\section{qPCR}

The total RNA samples were subjected to digestion with DNase I for $1 \mathrm{~h}$ at $37^{\circ} \mathrm{C}$. iScript cDNA Synthesis Kit (Bio-Rad, USA) and qScript microRNA cDNA Synthesis Kit (Quantabio, USA) were used to perform total RNA and miRNA reverse transcriptions, respectively. To measure the expression levels of MAGI2-AS3 and RECK mRNA, all qPCR reaction mixtures were prepared using BlazeTaq $^{\mathrm{Tm}}$ SYBR Green qPCR Mix (Genecopoeia, Guangzhou, China) with GAPDH as endogenous control. To measure the expression levels of miR-25, all qPCR reaction mixtures were prepared using miScript SYBR Green PCR Kit (QIAGEN) with U6 as endogenous control. All PCR reactions were performed 3 times. $2^{-\Delta \Delta C T}$ method was used for data normalizations. The sample with the biggest $\Delta C T$ value was set to value "1", and all other samples were normalized to this sample to calculate the relative expression levels. Amplification efficiencies of all primer pairs were between 95 and $100 \%$. PCR products were randomly selected and sequenced. All sequenced PCR products were correct.

\section{Western blot}

Total proteins in $\mathrm{H} 1993$ cells were extracted using RIPA solution (Sangon). Before, electrophoresis (10\% SDSPAGE gel), all protein samples were denatured in boiled water for $10 \mathrm{~min}$. After electrophoresis, proteins were transferred to PVDF membranes, followed by blocking in 5\% non-fat milk for $1 \mathrm{~h}$. PVDF membranes were first blotted by rabbit primary antibodies of GAPDH (1: 1300, ab37168, Abcam) and RECK (1: 1300, ab115844, Abcam) for at least $15 \mathrm{~h}$ at $4{ }^{\circ} \mathrm{C}$, followed by blotting with HRP goat anti-rabbit (IgG) antibody (1:1000; ab6721; Abcam) for $90 \mathrm{~min}$ at $25^{\circ} \mathrm{C}$. Signals were developed using RapidStep ${ }^{\text {тм }}$ ECL detection reagent from EMD Millipore. Image J v1.46 software was used to normalize gray values. It is worth noting that with $\beta$ actin as internal control, the same data were obtained. 
Cell invasion and migration analysis

H1993 cells were mixed with serum-free RPMI-1640 medium to prepare single cell suspensions $\left(3 \times 10^{4}\right.$ cells per well). $0.1 \mathrm{ml}$ suspension (serum-free) was added into Transwell upper chamber. The low chamber was added with RPMI-1640 medium containing 20\% (W/V) FBS. Upper chamber membrane was coated with Matrigel (Millipore) at $37^{\circ} \mathrm{C}$ for $6 \mathrm{~h}$ before invasion assay. Transwell chambers were kept at $37^{\circ} \mathrm{C}$ for $15 \mathrm{~h}$ to allow cell invasion and migration. Following staining with $1 \%$ crystal violet (Sigma-Aldrich), cell images were obtained using a light microscope.

\section{Data analysis}

Experiments were performed in 3 independent replicates and mean values were used to express all data. Differences were explored between 2 types of tissues (non-tumor vs.
NSCLC) using paired t test. ANOVA (one-way) in combination with Tukey test were used to compare more than 2 groups. Linear regression was used to explore correlations. $p<0.05$ was considered statistically significant.

\section{Results}

MAGI2-AS3 and RECK were both downregulated and they were correlated in NSCLC

Expression levels of MAGI2-AS3 and RECK mRNA in two types of tissues (non-tumor and NCSLC) were measured by qPCR. Expression data were compared between two types of tissues by paired $t$ test. It can be observed that expression levels of MAGI2-AS3 (Fig. 1a) and RECK mRNA (Fig. 1b) were significantly lower in NSCLC tissues than those in non-tumor tissues $(p<0.05)$. Correlations between MAGI2-AS3 and RECK mRNA were analyzed by linear regression. It can be observed that, in NSCLC

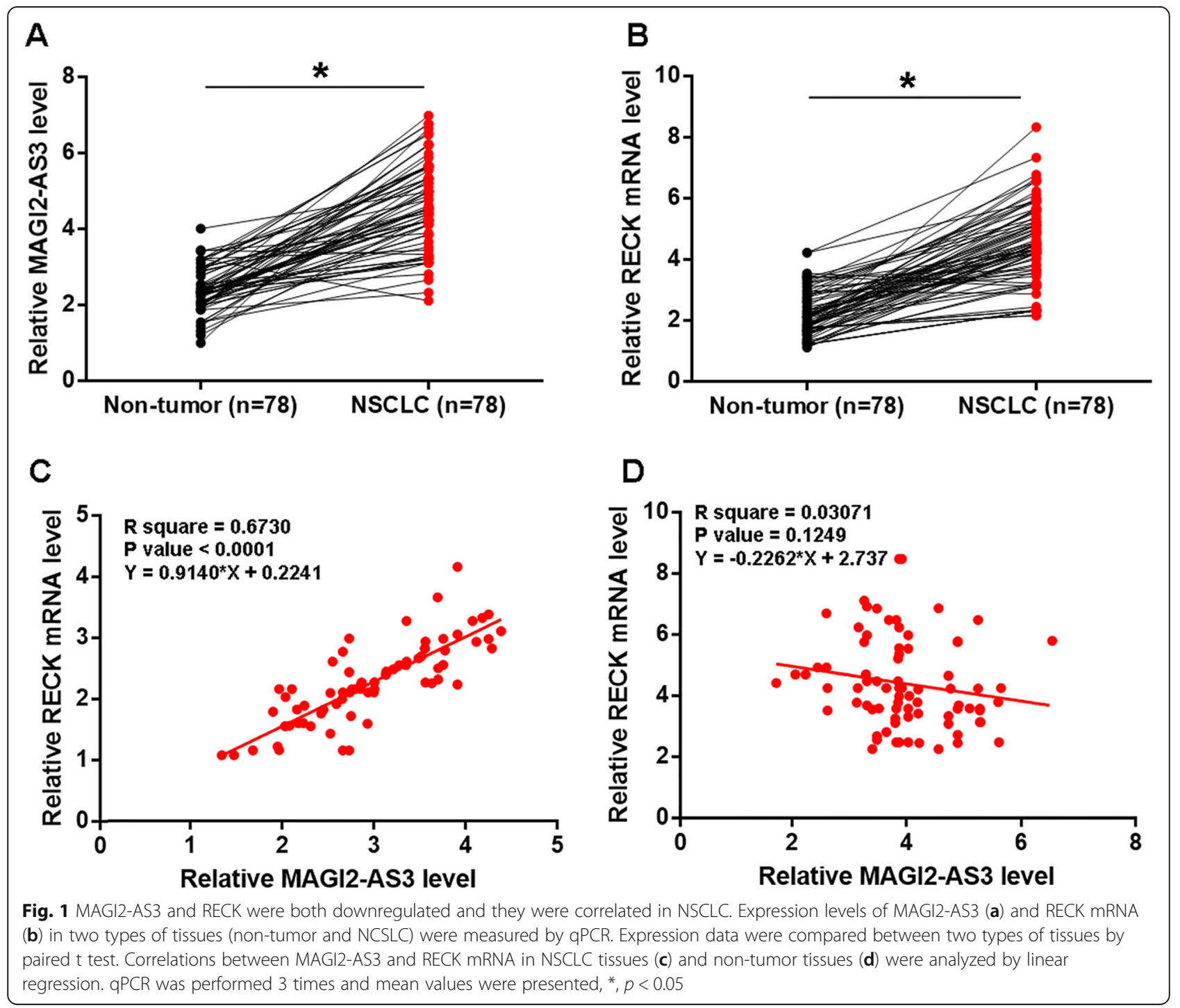


tissues, MAGI2-AS3 and RECK mRNA were significantly and positively correlated (Fig. 1c). However, in non-tumor tissues, MAGI2-AS3 and RECK mRNA were not significantly correlated (Fig. 1d).

\section{MAGI2-AS3 overexpression led to upregulated RECK in H1993 cells}

To further investigate the interaction between MAGI2AS3 and RECK, MAGI2-AS3 and RECK expression vectors were transfected into $\mathrm{H} 1993$ cells. At $24 \mathrm{~h}$ posttransfections, expression levels of MAGI2-AS3 and RECK were significantly increased comparing to NC and $\mathrm{C}$ groups (Fig. 2a, $p<0.05$ ). In addition, MAGI2-AS3 overexpression led to upregulated RECK at both mRNA and protein levels (Fig. 2b, $p<0.05$ ). In contrast, MAGI2-AS3 expression was not significantly affected by RECK overexpression (Fig. 2c).
MAGI2-AS3 may sponge miR-25 to upregulate RECK Bioinformatics analysis showed that MAGI2-AS3 may bind miR-25 (Fig. 3a). Comparing to NC and $\mathrm{C}$ groups, MAGI2-AS3 overexpression failed to miR-25 expression, and miR-25 overexpression also failed to affect MAGI2AS3 expression (Fig. 3b). Moreover, comparing to two controls, miR-25 overexpression led to downregulated RECK and attenuated the effects of MAGI2-AS3 overexpression (Fig. 3c, $p<0.05$ ).

MAGI2-AS3 inhibits NSCLC cell invasion and migration Cell invasion and migration analysis showed that, comparing to $\mathrm{NC}$ and $\mathrm{C}$ two groups, NSCLC cell invasion (Fig. 4a) and migration (Fig. 4b) rates were significantly decreased after MAGI2-AS3 and RECK overexpression $(p<0.05)$. MiR-25 reduced the effects of MAGI2-AS3 overexpression $(p<0.05)$.
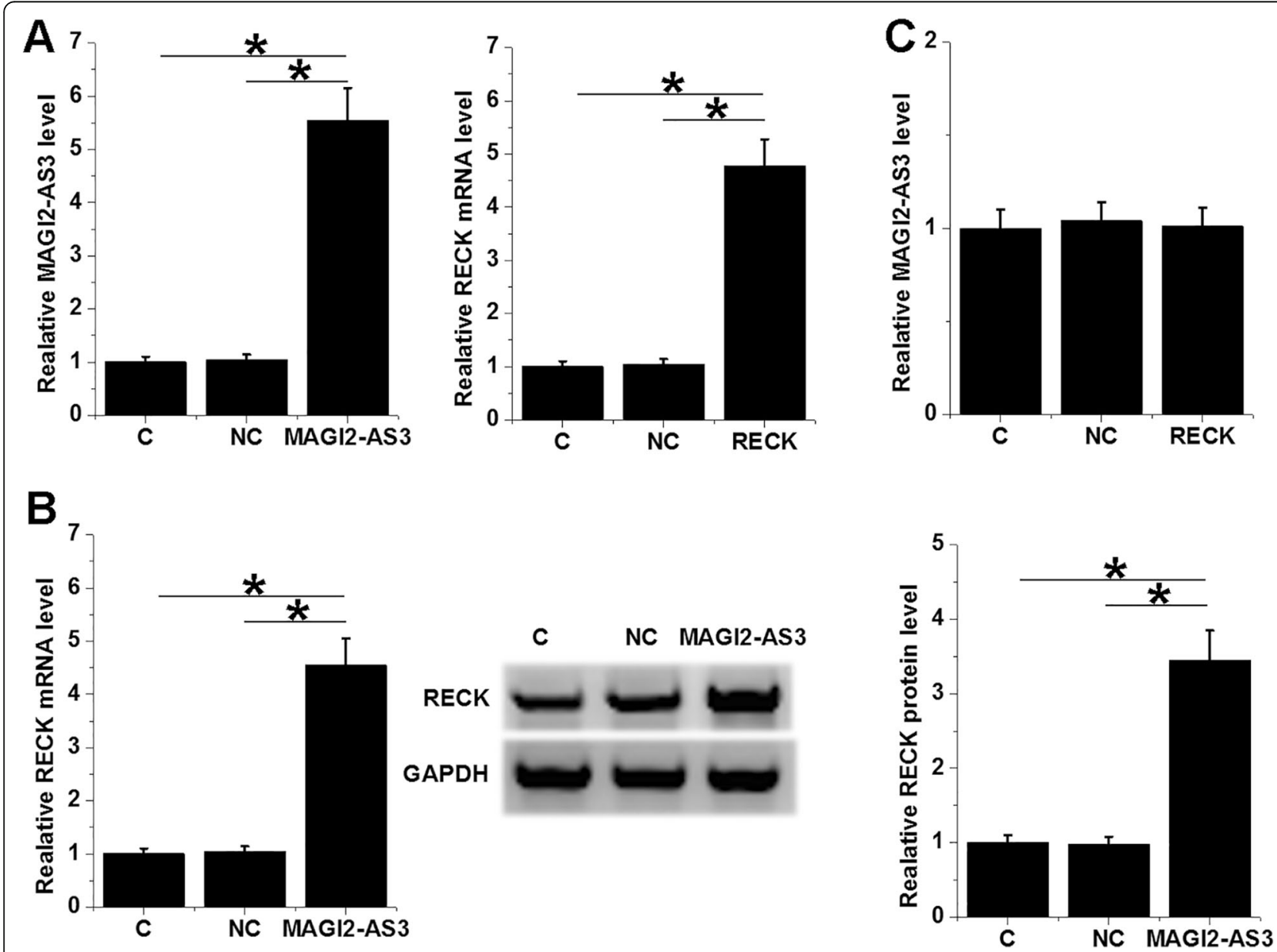

Fig. 2 MAGI2-AS3 overexpression led to upregulated RECK in H1993 cells. To further investigate the interaction between MAGI2-AS3 and RECK, MAGI2-AS3 and RECK expression vectors were transfected into $\mathrm{H} 1993$ cells. At $24 \mathrm{~h}$ post-transfections, overexpression of MAGI2-AS3 and RECK was confirmed by qPCR (a). The effects of MAGl2-AS3 overexpression on RECK expression were analyzed by qPCR and western blot (b). The effects of RECK overexpression on MAGI2-AS3 expression were analyzed by qPCR (c). Western blot and qPCR were performed 3 times and mean \pm SD values were presented. ${ }^{*}, p<0.05$ 

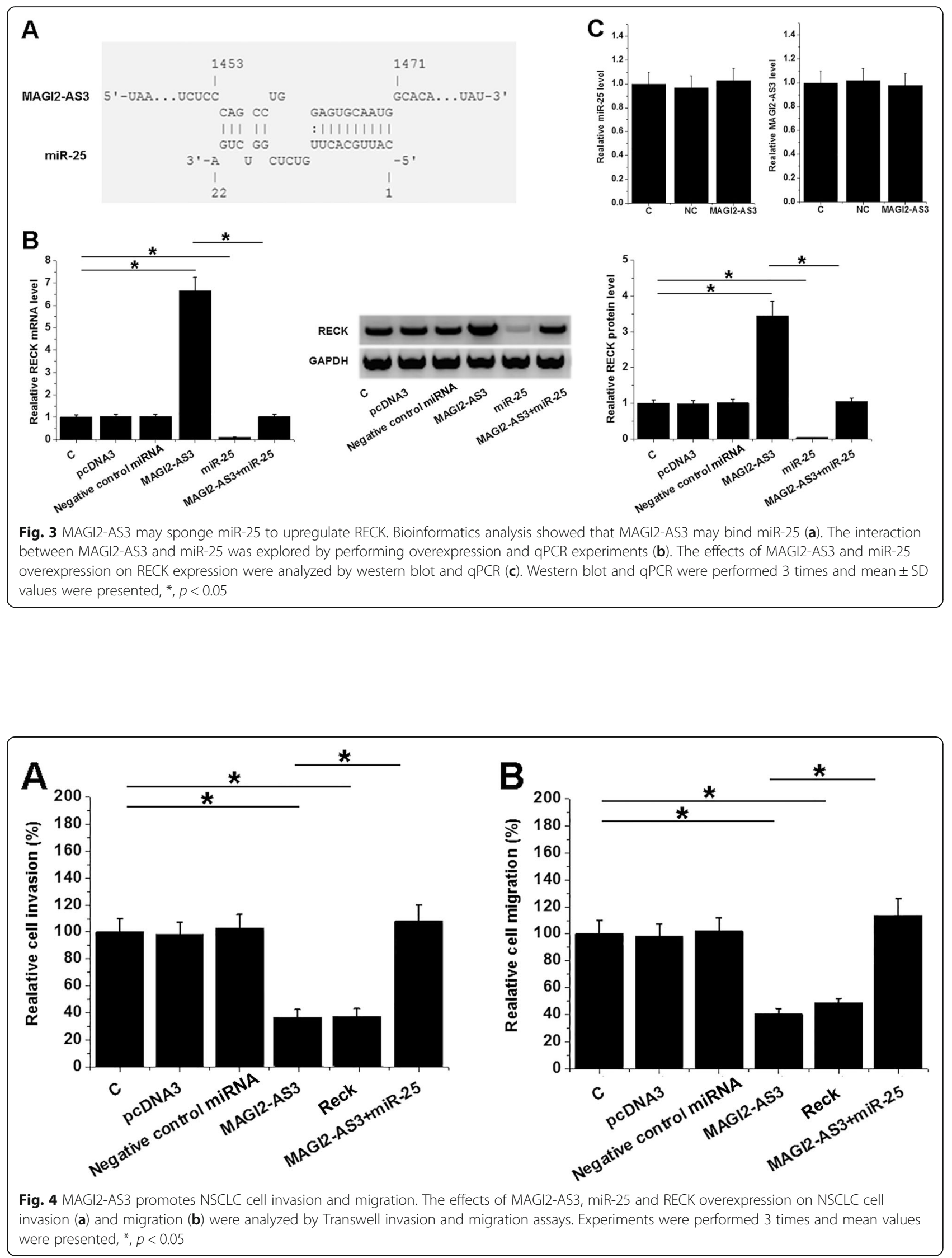


\section{Discussion}

In this study MAGI2-AS3 was characterized as a tumor suppressor in NSCLC. Moreover, we also found that MAGI2-AS3 may be a sponge of miR-25, and the interaction between MAGI2-AS3 and miR-25 led to upregulated RECK, which is a target of miR-25.

All previous studied on MAGI2-AS3 revealed its tumor suppressive roles in different types of cancers, such as breast cancer, bladder cancer and hepatocellular carcinoma [12-15]. However, MAGI2-AS3 may interact with different downstream targets to regulate different cell behaviors in different types of cancers [13-15]. In breast cancer, MAGI2-AS3 is an inhibitor of cancer cell growth and its roles in this process are mediated by its interactions with Fas/FasL [13]. In bladder cancer, MAGI2-AS3 mainly interacts with CCDC19 to inhibit the migration, proliferation and invasion of cancer cells [14]. In hepatocellular carcinoma, MAGI2-AS3 targets miR-374b-5p/SMG1 to inhibit proliferation and migration of HCC cells [15]. In this study we observed the downregulated expression of MAGI2-AS3 in NSCLC and its inhibitory effects on cancer cell migration and invasion. Our study proved MAGI2-AS3 as a tumor suppressor in NSCLC.

RECK has been characterized as a tumor suppressor in different types of cancers including NSCLC [16, 17]. Some miRNAs, such as miR-96 and miR-92b targets RECK to increase the invasiveness of NSCLC cells [16, 17]. It has been reported that miR-25 can also target RECK in gastric cancer to promote cell motility and growth [11]. In this study we also showed that miR-25 overexpression led to downregulated RECK expression at both mRNA and protein levels. Therefore, miR-25 may also target RECK in NSCLC. However, the upstream regulators of miR-25 in cancer biology have not been well studied. In this study we found that MAGI2AS3 may sponge miR-25. This conclusion is made due to the observation that MAGI2-AS3 overexpression did not affect miR-25 expression but upregulated its downstream target RECK. However, more studies are needed to further confirm this conclusion.

\section{Conclusion}

In conclusion, MAGI2-AS3 is an tumor suppressor in NSCLC and MAGI2-AS3 may sponge miR-25 to upregulate RECK, thereby promoting NSCLC invasion and migration.

\section{Abbreviation}

NSCLC: Non-small cell lung cancer

Acknowledgements

Not applicable.

\section{Authors' contributions}

Guarantor of integrity of the entire study: JKJ. Study concepts: JKJ. Study design: JKJ. Definition of intellectual content: JKJ. Literature research: YTS. Clinical studies: YTS. Experimental studies: YTS. Data acquisition: YTS. Data analysis: YTS. Statistical analysis: YTS. Manuscript preparation: YTS. Manuscript editing: YTS. Manuscript review: WCC, LF. All authors have read and approved the manuscript.

\section{Funding}

This work was supported by the Certificate of China Postdoctoral Science Foundation (Grant No. 2019M660030).

\section{Availability of data and materials \\ The analyzed data sets generated during the study are available from the corresponding author on reasonable request.}

\section{Ethics approval and consent to participate}

The present study was approved by the Ethics Committee of Heilongjiang University of Chinese Medicine. The research has been carried out in accordance with the World Medical Association Declaration of Helsinki. All patients and healthy volunteers provided written informed consent prior to their inclusion within the study.

\section{Consent for publication}

Not applicable.

\section{Competing interests}

The authors declare that they have no competing interests.

\section{Author details}

${ }^{1}$ National Cancer Center/National Clinical Research Center for Cancer/Cancer Hospital, Chinese Academy of Medical Sciences and Peking Union Medical College, Beijing 100021, China. ${ }^{2}$ Heilongjiang University of Chinese Medicine, Harbin 150040, Heilongjiang province, China. ${ }^{3}$ First Affiliated Hospital, Heilongjiang University of Chinese Medicine, Heping Road 26, Harbin 150040, Heilongjiang province, China.

Received: 22 August 2019 Accepted: 27 January 2020

Published online: 05 March 2020

\section{References}

1. Siegel R, Naishadham D, Jemal A. Cancer statistics, 2013. CA Cancer J Clin. 2013;63:11-30.

2. Bray F, Ferlay J, Soerjomataram I, et al. Global cancer statistics 2018: GLOBOCAN estimates of incidence and mortality worldwide for 36 cancers in 185 countries. CA Cancer J Clin. 2018;68(6):394-424.

3. Torre LA, Siegel RL, Jemal A. Lung cancer statistics. In: Lung cancer and personalized medicine. Cham: Springer; 2016. p. 1-19.

4. Islami F, Torre LA, Jemal A. Global trends of lung cancer mortality and smoking prevalence. Transl Lung Cancer Res. 2015;4(4):327-38.

5. Gazdar AF, Zhou C. Lung cancer in never-smokers: a different disease. In: IASLC Thoracic Oncology. Content Repository Only! 2018. p. 23-29. e3.

6. Brennan $P$, Hainaut $P$, Boffetta $P$. Genetics of lung-cancer susceptibility. Lancet Oncol. 2011:12(4):399-408.

7. Clark JCM, Thomas DM, Choong PFM, et al. RECK-a newly discovered inhibitor of metastasis with prognostic significance in multiple forms of cancer. Cancer Metastasis Rev. 2007;26(3-4):675-83.

8. Miki T, Takegami $Y$, Okawa $K$, et al. The reversion-inducing cysteine-rich protein with Kazal motifs (RECK) interacts with membrane type 1 matrix metalloproteinase and CD13/aminopeptidase N and modulates their endocytic pathways. J Biol Chem. 2007;282(16):12341-52.

9. Liu LT, Chang HC, Chiang LC, et al. Histone deacetylase inhibitor upregulates RECK to inhibit MMP-2 activation and cancer cell invasion. Cancer Res. 2003;63(12):3069-72

10. Hirata H, Ueno K, Shahryari V, et al. Oncogenic miRNA-182-5p targets Smad4 and RECK in human bladder cancer. PLoS One. 2012;7(11):e51056.

11. Zhao $H$, Wang $Y$, Yang $L$, et al. MiR-25 promotes gastric cancer cells growth and motility by targeting RECK. Mol Cell Biochem. 2014;385(1-2):207-13.

12. Thomson DW, Dinger ME. Endogenous microRNA sponges: evidence and controversy. Nat Rev Genet. 2016;17(5):272-83. 
13. Yang $\mathrm{Y}$, Yang $\mathrm{H}$, Xu M, et al. Long non-coding RNA (IncRNA) MAGI2-AS3 inhibits breast cancer cell growth by targeting the Fas/FasL signalling pathway. Hum Cell. 2018;31(3):232-41.

14. Wang F, Zu Y, Zhu S, et al. Long noncoding RNA MAGI2-AS3 regulates CCDC19 expression by sponging miR-15b-5p and suppresses bladder cancer progression. Biochem Biophys Res Commun. 2018:507(1-4):231-5.

15. Yin Z, Ma T, Yan J, et al. LncRNA MAGI2-AS3 inhibits hepatocellular carcinoma cell proliferation and migration by targeting the miR-374b-5p/ SMG1 signaling pathway. J Cell Physiol. 2019. https://doi.org/10.1002/jcp. 28521.

16. Guo H, Li Q, Li W, et al. MiR-96 downregulates RECK to promote growth and motility of non-small cell lung cancer cells. Mol Cell Biochem. 2014; 390(1-2):155-60

17. Lin HY, Chiang CH, Hung WC. STAT3 upregulates miR-92a to inhibit RECK expression and to promote invasiveness of lung cancer cells. $\mathrm{Br} J$ Cancer. 2013;109(3):731-8

\section{Publisher's Note}

Springer Nature remains neutral with regard to jurisdictional claims in published maps and institutional affiliations.

Ready to submit your research? Choose BMC and benefit from:

- fast, convenient online submission

- thorough peer review by experienced researchers in your field

- rapid publication on acceptance

- support for research data, including large and complex data types

- gold Open Access which fosters wider collaboration and increased citations

- maximum visibility for your research: over $100 \mathrm{M}$ website views per year

At BMC, research is always in progress.

Learn more biomedcentral.com/submissions 